\title{
LARGE PERPENDICULAR-ANISOTROPY, HIGH-COERCIVITY CO-Pt ALLOYS FOR
}

MAGNETO-OPTICAL RECORDING.

\author{
R.F.C. Farrow, R.H. Geiss, G.L. Gorman, G.R. Harp, R.F. Marks and E.E. Marinero \\ IBM Research Division, Almaden Research Center, 650 Harry Road, San Jose, CA \\ 95120-6099, USA.
}

\begin{abstract}
We report the development of $\mathrm{Co}-\mathrm{Pt}$ alloy films with large perpendicular anisotropy and high coercivity ( $>4 \mathrm{kOe}$ ) grown directly onto amorphous, non-metallic substrates. This has made possible magneto-optical rccording in these alloys with CNR values exceeding, for the first time, $57 \mathrm{~dB}$ at $488 \mathrm{~nm}$.
\end{abstract}

\section{KEYWORDS: Co-Pt, ALLOY, PERPENDICULAR ANISOTROPY, MAGNETO-OPTICAL RECORDING.}

\section{INTRODUCTION}

High-vacuum evaporation of Co-Pt alloy films, for magneto-optical recording has recently been reported by Weller et al.[1]. Such alloy films have the advantages in this application over $\mathrm{Co} / \mathrm{Pt}$ multilayers or rare earth-based amorphous alloys of simplicity in growth and larger MO signal[1], especially in the blue spectral region. However, a road block to the utilization of such alloys is their low coercivity ( $\$ 1 \mathrm{kOe}$ ) when grown on diejectric underlayers such as amorphous SiN films or fused silica (quartz) substrates. This leads to difficulties in writing stable marks for MO recording and to a low carrier to noise (CNR) ratio of $\$ 50 \mathrm{~d}$ B. In this paper we report the structural and magnetic characterization of polycrystalline $\mathrm{Co}_{x} \mathrm{Pt}_{1-x}(\mathrm{x} \sim 0.25)$ alloy films deposited onto substrates of amorphous carbon, amorphous SiN and fused silica at temperatures ranging from 30 to $500^{\circ} \mathrm{C}$. The results are compared with those for highly [111] oriented epitaxial alloy films grown onto basal-plane sapphire substrates under identical conditions.

Perpendicular anisotropy and maximum (as a function of deposition temperature) coercivities $\geq 4 \mathrm{kOc}$ are achieved for polycrystalline films deposited, at $\sim 300^{\circ} \mathrm{C}$, on all amorphous substrates. On the other hand, the epitaxial films exhibit perpendicular anisotropy and a significantly lower maximum coercivity at this temperature. Structural characterization of the films by
$X$-ray diffraction and transmission electron microscopy (TEM) reveals that the maximum in coercivity occurs near the onset of chemical ordering in the films.

\section{EXPERIMENTAL TECHNIQUES}

The films were grown in a MBE system (VG Semicon-Fisons VG $80 \mathrm{M}$ ) in a background pressure of below $2 \times 10^{-10}$ Torr. Co-evaporation from elcctron heam sources for $\mathrm{Co}$ and $\mathrm{Pt}$ was used and the respective growth rates were $\approx 0.034 \mathrm{~A} / \mathrm{s}$ for $\mathrm{Co}$ and $\approx 0.111 \mathrm{~A} / \mathrm{s}$ for $\mathrm{Pt}$. Films of $\sim 200 \AA$ thick were deposited onto a variety of amorphous substrates including amorphous carbon films $(\sim 100 \AA$ thick) on mica and SiN films on amorphous carbon on mica. The strategy for using carbon films was to facilitate transmission electron microscopy of the alloys. Foils for transmission electron microscopy were formed by simply detaching the carbon films from mica. This method worked for a wide range of substrate temperatures from 30 to $500^{\circ} \mathrm{C}$ permitting the structural examination of alloy films grown within this temperature range. Additionally, films were grown directly onto silica, carbon on silica, SiN on silica, carbon on silicon (111), silicon (111), carbon on basal-plane sapphirc and basal-plane sapphire. The magnetic propertics oi the films were studied using polar Kerr magnetometry, vibrating sample magnetometry (VSM) and trirque magnetometry. Transmission electron microscony was carried out using JEOL 4000EX $(400 \mathrm{keV})$ and Akashi $(200 \mathrm{keV})$ electron microscopes. 
$X$-ray diffraction studies were carried out using a Siemens diffractometer for $\theta-2 \theta$ scans and rocking curve scans.

\section{EXPERIMENTAL RESULTS}

Figure 1 shows polar Kerr loops $(633 \mathrm{~nm})$ recorded from a series of films of composition $\mathrm{x} \approx 0.24,200 \AA$ thick grown at different growth temperatures onto carbon on mica. There is a progressive increase in perpendicular anisotropy and coercivity from 30 to $300^{\circ} \mathrm{C}$. Above this temperature the perpendicular anisotropy and coercivity collapse and the anisotropy is in-plane at $500^{\circ} \mathrm{C}$. This trend was also found for films grown directly onto basal-plane sapphire substrates. In this case the films were highly oriented with [111] as the growth axis.

Figure 2 shows the temperature dependence of cocrcivity for both sets of films. The coercivity peaks at a growth temperature of $\approx 300^{\circ} \mathrm{C}$ for both sets of films although the peak coercivity of the epitaxial films is significantly lower.

Figure 3 shows X-ray rocking curves for a film of $\mathrm{CoPt}_{3}$ grown simultaneously onto carbon on mica and directly onto basal-plane sapphire at $300^{\circ} \mathrm{C}$. Note that the lattice constant of $\mathrm{CoPt}_{3}(3.829 \AA)$ is only $2 \%$ smaller than the in-plane spacing of hollow sites in the O-terminated surface of sapphire. This geometric fit leads to highly oriented [111] growth of $\mathrm{CoPt}_{3}$ on sapphire. In fact, the film grows with a $180^{\circ}$ twinning of $\mathrm{Pt}$ about the [111]

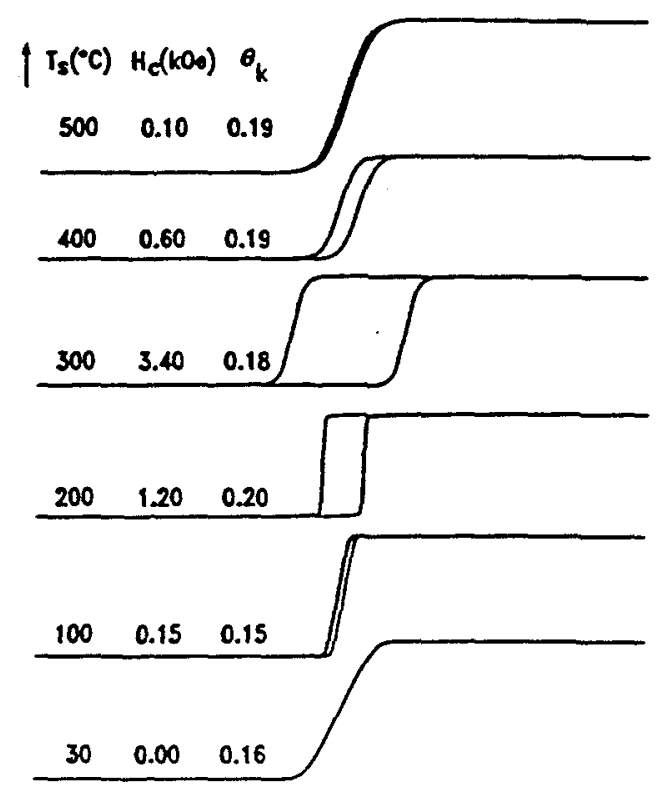

Figure 1.

Polar Kerr loops $(633 \mathrm{~nm})$ for polycrystalline films of $\mathrm{CoPt}_{3}$ on mica substrates. axis. The rocking curve of the epitaxial film is only $0.7^{\circ}$ FWHM compared with $\approx 20^{\circ}$ for the alloy film grown on amorphous carbon. This latter film has little or no preferred texture and the $\theta-2 \theta$ scans reveal (002), (022), (311) and other orientations in the film.

The polycrystalline film has a much greater coercivity than the epitaxial film as shown by comparison of polar

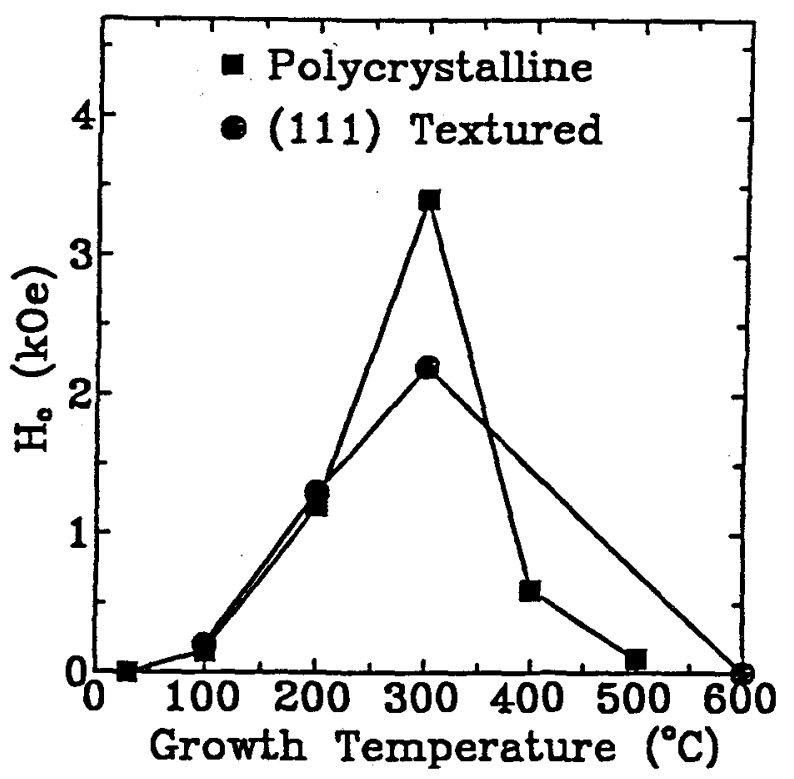

Figure 2.

Coercivity versus substrate temperature for polycrystalline and epitaxial films of $\mathrm{CoPt}_{3}$

Kerr loops (Figure 3) for the two samples. This behaviour contrasts with that for $\mathrm{Co} / \mathrm{Pt}$ multilayers[2,3] where for films without [111] texture the magnetic anisotropy was in-plane for Co thicknesses $\gtrsim 5 \AA$. Subsequent studies[4] of alloy films, grown epitaxially along the 3 three major axes of the alloy, show that the perpendicular anisotropy is largely independent of growth orientation, but that orientation does influence the coercivity of the alloy films. The high coercivity and relatively square loop for the polycrystalline sample is advantageous for preparation of films for MO media. Unlike $\mathrm{Co} / \mathrm{Pt}$ multilayers, it is not necessary to optimize the texture axis.

Table 1 summarizes the anisotropy energy for films grown onto various substrates. Note that the anisolropy energy $\left(\mathrm{K}_{\mathrm{u}}\right)$ tracks with coercivity for these samples and is lowest for the epitaxial film grown onto basal-planc sapphire. Measurements of anisotropy encrgies and coercivities for alloy films grown onto SiN films on glass 

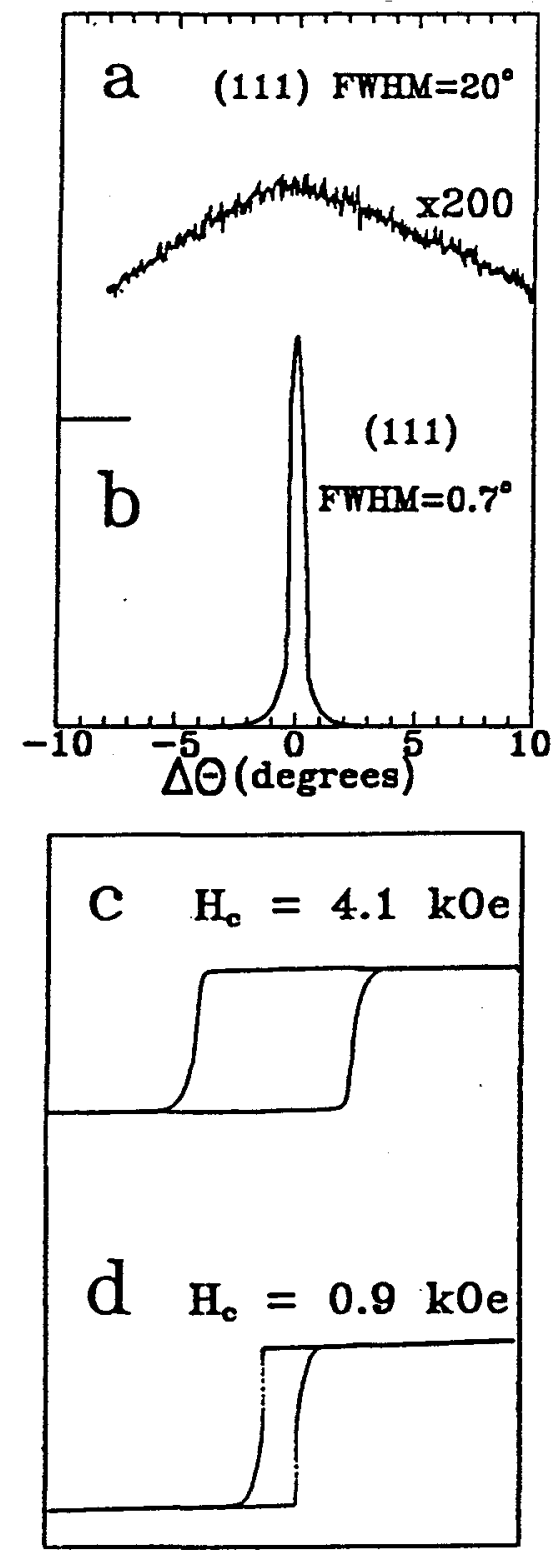

Figure 3.

$X$-ray rocking curves for alloy (111) peak:

(a) for $\mathrm{CoPt}_{3}$ on carbon film on mica.

(b) for $\mathrm{CoPt}_{3}$ on sapphire (0001).

(c), (d) corresponding polar Kerr loops. $\theta_{k}=0.2^{\circ}$ in both cases.

and silica revealed values similar to that for deposition on silica.

Transmission electron microscony studies were carried out on alloy films grown onto carbon on mica at 30, 100, $200,300,400$ and $500^{\circ} \mathrm{C}$. In addition, films grown onto $\mathrm{SiN}$ on carbon at $300 \mathrm{C}$ were also examined. It was found that the grain size of the films increased smoothly with temperature but that there was a greater spread in grain size for the films grown above $300^{\circ} \mathrm{C}$. This illustrated by

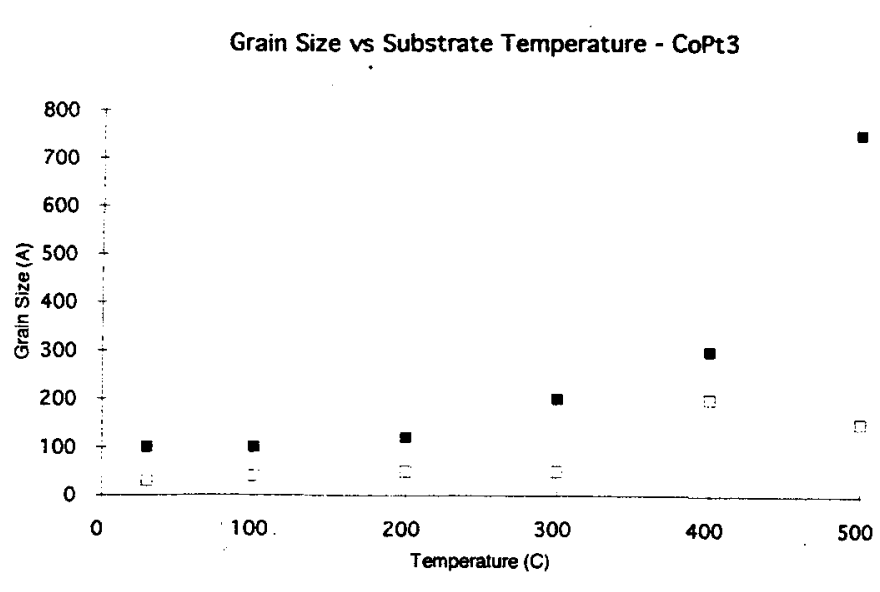

Figure 4.

Plot of grain size versus growth temperature for $200 \AA$-thick polycrystalline $\mathrm{CoPt}_{3}$ films on amorphous carbon on mica.

the plot of grain size versus growth temperaturc shown in Figure 4. Note that the pairs of data points, at each temperature, indicate the spread in grain size.

In films grown above $300^{\circ} \mathrm{C}$ rings of extra diffraction spots were observed. which corresponded to superstructure diffraction from the chemically ordered

$\mathrm{LI}_{2}$ phase. Isolated clusters of this phase were observed in films grown at $500^{\circ} \mathrm{C}$ (see Figure 5). At $400 \mathrm{C}$ the clusters are more dispersed whilst at $300^{\circ} \mathrm{C}$ they are barely detectable by TEM diffraction or imaging. However, recent synchrotron X-ray diffraction studies[4] has confirmed that chemical ordering is present in both polycrystalline and epitaxial alloy films grown at $300^{\circ} \mathrm{C}$. The coherence length for chemical ordering at $300^{\circ} \mathrm{C}$ is, however, very short $(<8 \AA)$.

\section{DISCUSSION}

The growth of high coercivity $\mathrm{CoPt}_{3}$ alloy films prepared on amorphous substrates has opened up the prospect for alloy media MO discs. We have prepared quadrilayer structures comprising: glass disc / 400 $\AA$ SiN / 200A $\mathrm{CoPt}_{3} / 200 \AA \mathrm{SiN} / 500 \AA \mathrm{Al}$. Dynamic testing at $488 \mathrm{~nm}$ has been carried out and a CNR value of $57.5 \mathrm{~dB}$ obtained. Further refinements of the structure can be expected to improvements in CNR.

The development of perpendicular anisotropy may be related to the onset of partial chemical ordering [5] in the film at $\sim 300^{\circ} \mathrm{C}$. At this temperature a dispersion of the ordered phase exists [4] and the 
Proceedings of Magneto-Optical Recording International Symposium '92, J. Magn. Soc. Jpn., Vol. 17, Supplement No. S1 (1993), pp. 140-144 1993 by The Magnetics Society of Japan

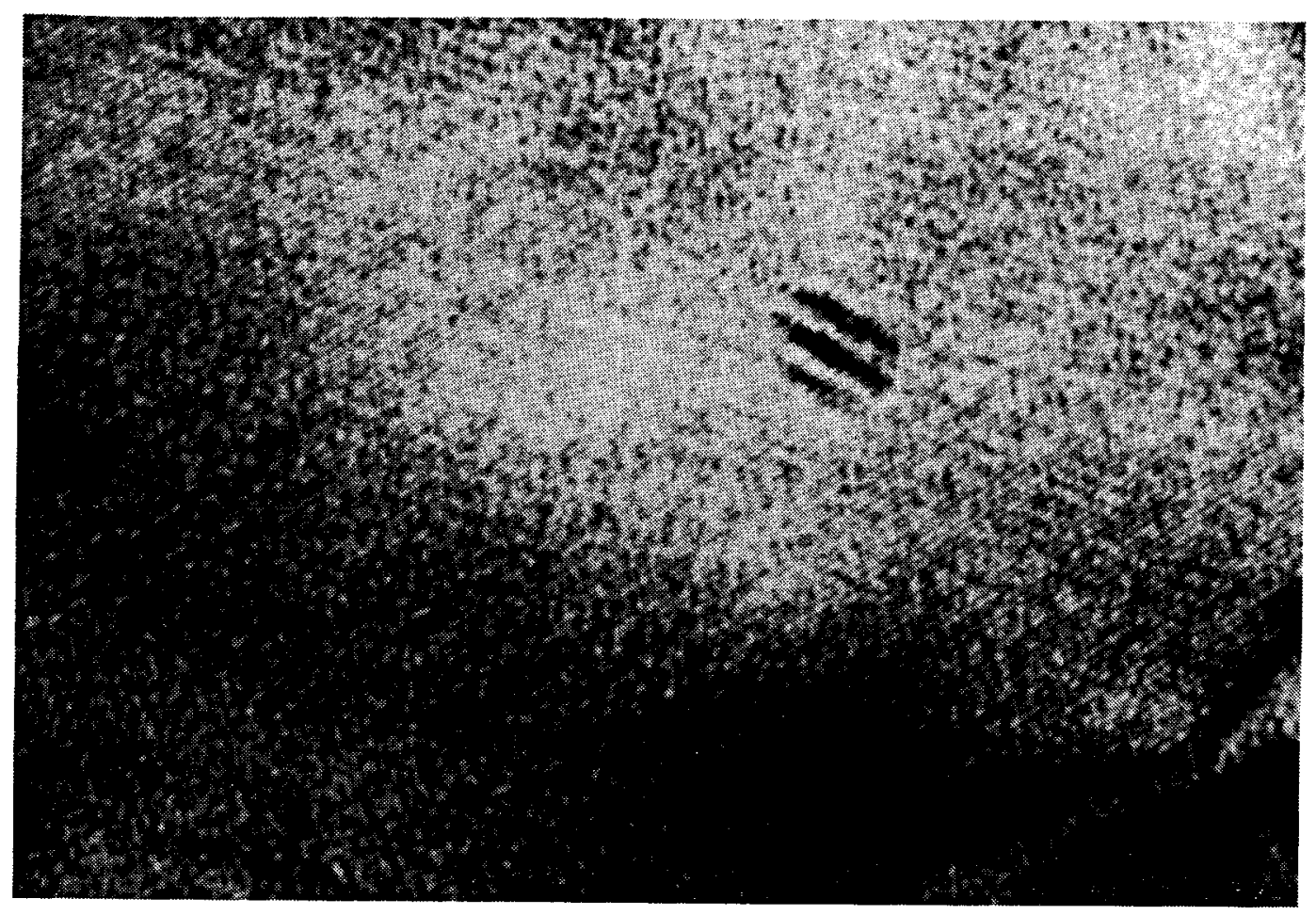

Figure 5.

\begin{abstract}
High-resolution plan-view micrograph showing an ordered $\mathrm{L1}_{2}$ region within a grain of a $\mathrm{CoPt}_{3}$ film grown at $500^{\circ} \mathrm{C}$. The ordered region is about $30 \AA$ across and the lattice fringes are from (111) planes; the fringe spacing is $2.21 \AA$.
\end{abstract}

TABLE 1.

Anisotrony Energies $\left(\mathrm{K}_{\mathrm{U}}\right.$ ) for $200 \AA \mathrm{CoPt}$ Films grown onto various substrates at $300^{\circ} \mathrm{C}$.

\begin{tabular}{|l|l|l|l|}
\hline Substrate & Film structure & $\mathbf{H}_{\mathrm{c}}(\mathbf{k O e})$ & $\mathbf{K}_{\mathrm{u}}\left(\mathrm{erg} / \mathrm{cm}^{3}\right)$ \\
\hline $\mathrm{c} / \mathrm{Al}_{2} \mathrm{O}_{3}$ & poly & 4.4 & $2.67 \times 10^{6}$ \\
\hline $\mathrm{Al}_{2} \mathrm{O}_{3}$ & epitaxial & 0.9 & $1.68 \times 10^{6}$ \\
\hline c/silicon $(1 \mathrm{II})$ & poly & 4.3 & $2.45 \times 10^{6}$ \\
\hline silica & poly & 5.5 & $3.84 \times 10^{6}$ \\
\hline
\end{tabular}

coherence length of this phase may be anisotropic. If the ordered regions are lamellar and parallel to the film plane then more $\mathrm{Co}-\mathrm{Co}$ pairs will exist along the film normal since the ordered phase contains no Co-Co nearest neighbors. This could give the uniaxial anisotrony observed. At temperatures below $300^{\circ} \mathrm{C}$ there is negligible ordering whilst at temperatures above $300^{\circ} \mathrm{C}$ the ordered regions may become condensed into clusters, via both lateral and vertical diffusion. The anisotropy in coherence length will then be suppressed leading to a poak in perpendicular anisotropy with substrate temperature, as we observe. This idca is tentative and is prescntly being 
tested by synchrotron diffraction and EXAFS. This will be the subject of a future publication.

\section{CONCLUSIONS}

- High perpendicular anisotropy, high $(\sim 4 \mathrm{kOe})$ coercivity $\mathrm{CoPt}_{3}$ alloy films have been grown on a variety of amorphous dielectric substrates.

- The coercivity and anisotropy depend on deposition temperature and a peak coercivity is reached at $\sim 300^{\circ} \mathrm{C}$ for growth of the alloy on both amorphous and single crystal-sapphire substrates.

- Dynamic writing experiments have demonstrated a CNR of $57.5 \mathrm{~dB}$ at $488 \mathrm{~nm}$.

- A tentative model for the magnetic anisotropy is suggested.

\section{REFERENCES}

1. D. Weller, H. Brändle, G. Gorman, C.-J.Lin, H. Notarys, Appl. Phys. Lett. (accepted) (1992).

2. C.H. Lee, R.F.C. Farrow, C.J. Lin, E.E. Marinero, C.J. Chien, Phys. Rev.B, 42, 11384 (1990).

3. R.F.C. Farrow, C.H. Lee, R.F. Marks, G.R. Harp, M.F. Toney, T.A. Rabedeau, D. Weller, H. Brändle, Proceedings of NATO Advanced Research Workshop on "Magnetism and Structure in Systems of Reduced Dimension". Cargèse, France June 15-20, 1992. In press, Plenum Publishing Co..

4. T.A. Rabedeau, M.F. Toney, R.F.C. Farrow, G.R. Harp, R.F. Marks, to be submitted to J. Appl. Phys.

5. The idea of anisotropic coordination in a dispersed, ordered $\mathrm{CoPt}_{3}$ phase contributing to magnetic anisotropy in Co-Pt films was proposed by Chien et al., J. Mag. Mag. Mat. 93, 47 (1991). 